\title{
Genetic differences in osteogenic differentiation potency in the thoracic ossification of the ligamentum flavum under cyclic mechanical stress
}

\author{
SHANGLONG NING ${ }^{1,2}$, ZHONGQIANG CHEN ${ }^{1}$, DONGWEI FAN ${ }^{1}$, CHUIGUO SUN $^{1}$, CHI ZHANG $^{3}$, \\ YAN ZENG ${ }^{1}$, WEISHI LI ${ }^{1}$, XIAOFEI HOU ${ }^{1}$, XIAOCHEN QU ${ }^{1}$, YUNLONG MA ${ }^{1}$ and HUILEI YU ${ }^{1}$ \\ ${ }^{1}$ Department of Orthopedics, Peking University Third Hospital, Beijing 100191; ${ }^{2}$ Department of Spine Surgery, \\ Tianjin Hospital, Tianjin 300211, P.R. China; ${ }^{3}$ Bone Research Laboratory, University of Texas \\ Southwestern Medical Center, Dallas, TX 75390, USA
}

Received June 24, 2016; Accepted November 2, 2016

DOI: $10.3892 / \mathrm{ijmm} .2016 .2803$

\begin{abstract}
Mechanical stress and genetic factors play important roles in the occurrence of thoracic ossification of ligament flavum (TOLF), which can occur at one, two, or multiple levels of the spine. It is unclear whether single- and multiple-level TOLF differ in terms of osteogenic differentiation potency and osteogenesis-related gene expression under cyclic mechanical stress. This was addressed in the present study using patients with non-TOLF and single- and multiple-level TOLF ( $\mathrm{n}=8$ per group). Primary ligament cells were cultured and osteogenesis was induced by application of cyclic mechanical stress. Osteogenic differentiation was assessed by evaluating alkaline phosphatase (ALP) activity and the mRNA and protein expression of osteogenesis-related genes, including ALP, bone morphogenetic protein 2 (BMP2), Runt-related transcription factor-2 (Runx-2), osterix, osteopontin (OPN) and osteocalcin. The application of cyclic mechanical stress resulted in higher ALP activity in the multiple-level than in the single-level TOLF group, whereas no changes were observed in the non-TOLF group. The ALP, BMP2, OPN and osterix mRNA levels were higher in the multiple-level as compared to the single-level
\end{abstract}

Correspondence to: Dr Zhongqiang Chen, Department of Orthopedics, Peking University Third Hospital, 49 North Garden Road, Beijing 100191, P.R. China

E-mail: puth_chenzq@126.com

Abbreviations: TOLF, thoracic ossification of ligamentum flavum; ALP, alkaline phosphatase; BMP2, bone morphogenetic protein 2; OPN, osteopontin; OCN, osteocalcin; COL6A1, collagen type VI alpha1; HLA-DQA1, major histocompatibility complex, class II, DQ $\alpha 1$; OPLL, ossification of posterior longitudinal ligament; RIPA, radioimmunoprecipitation; BCA, bicinchoninic acid; $\mathrm{Ct}$, cycle threshold; GAPDH, glyceraldehyde-3-phosphate dehydrogenase; ANOVA, oneway analysis of variance

Key words: thoracic ossification of ligamentum flavum, multi-level TOLF, single-level TOLF, osteogenic differentiation potency, genetic difference
TOLF group, and the levels of all osteogenesis-related genes, apart from Runx2, were higher in the multiple-level as compared to the non-TOLF group. The osterix and ALP protein levels were higher in the multiple-level TOLF group than in the other 2 groups, and were increased with the longer duration of stress. These results highlight the differences in osteogenic differentiation potency between single- and multiple-level TOLF that may be related to the different pathogenesis and genetic background.

\section{Introduction}

Ossification of the ligamentum flavum (OLF) of the spine is characterized by ectopic bone formation in the ligament flavum and is highly prevalent in the population of East Asia, including the Japanese and Chinese populations (1-4). Epidemiological studies have demonstrated that OLF frequently occurs in the thoracic spine. Thoracic OLF (TOLF) progresses insidiously over a long period of time, resulting in devastating spinal cord injury that invariably leads to serious myelopathy. Many factors contribute to OLF, including genetic background, dietary habits, metabolic abnormalities and mechanical stress (5-7).

TOLF most often affects one or two levels of the spine and presents mainly in the lower thoracic spine (T10-T12) (8), which is a mobile transition region that may be more prone to degeneration owing to the high tensile forces in the posterior column. Axial mechanical overload and the consequent increase in repetitive tensile strain on ligamentum tissues contribute to TOLF (9). Additionally, we have previously found that mechanical stress induces the osteogenic differentiation of cells from patients with $\operatorname{TOLF}(6,10)$. Thus, local abnormal mechanical stress is thought to contribute to the progression of TOLF. However, there are also many cases of multiple-level TOLF in immobile, as well as mobile segments that differ from single-level lesions in terms of disease progression and clinical outcomes (11-13). On the basis of the whole clinical condition, we hypothesized that TOLF involving multiple levels extensively and TOLF in the circumscribed region may have a different pathogenesis. Probably on the account of the differences in genetic background, the osteogenic differentiation potency may be intrinsically greater in multiple-level TOLF than in single-level TOLF. 
During osteogenic differentiation, transcription factors, such as osterix and Runt-related transcription factor-2 (Runx2) and osteogenesis-related genes, such as bone morphogenetic protein (BMP)2 regulate the expression of osteoblast markers, including alkaline phosphatase (ALP), osteopontin (OPN), and osteocalcin (OCN) among others (7,14-16). Susceptibility genes, including collagen type VI alpha1 (COL6A1), BMP4 and major histocompatibility complex, class II, DQ alpha1 (HLA-DQA1) have also been shown to be associated with the occurrence of $\operatorname{TOLF}(17,18)$.

To date, single- and multiple-level TOLF have not been investigated as separate conditions and there have been no comparative studies examining differences in osteogenic differentiation potency and related gene expression, at least to the best of our knowledge. Only a similar and preliminary research was conducted on the ossification of the posterior longitudinal ligament (OPLL) (19). Thus, this was addressed in the present study using spinal ligament samples obtained from patients with single- and multiple-level TOLF in which osteogenic differentiation was induced by the application of cyclic mechanical stress.

\section{Materials and methods}

Clinical diagnosis and spinal ligament samples. The diagnosis of TOLF or non-TOLF (i.e., other thoracic diseases) was confirmed by pre-operative radiography, computed tomography and magnetic resonance imaging (MRI) of the whole spine. We previously established a TOLF classification scheme based on lesion distribution in MRI (20), as follows (Fig. 1): circumscribed (ossification in 2 or fewer adjacent levels), continuous (continuous ossification in 3 or more levels) and intermittent (intermittent distribution of local or continuous ossification). To assess genetic differences in the osteogenic differentiation potency among lesion types, a comparative analysis of single- and multiple-level TOLF ( 1 and $\geq 5$ levels, respectively) was performed. Non-TOLF specimens were obtained from patients with other thoracic spine diseases, such as trauma or disc herniation, who had no ossification in any spinal ligaments. Spinal ligament tissue specimens and associated clinical diagnoses in this study are shown in Table I and Fig. 2. Single- and multiple-level TOLF and non-TOLF ligaments were aseptically obtained from patients during surgery and ligaments were obtained from non-ossified sites to avoid any possible contamination of osteogenic cells. This study was approved by the Ethics Committee of Peking University Third Hospital (Beijing, China) and all patients provided written informed consent prior to obtaining the samples.

Cell culture. Cell culture was conducted as previously described (21). The ligament specimens were minced into $0.5-\mathrm{mm}^{3}$ sections and digested with $0.25 \%$ trypsin (Gibco, Grand Island, NY, USA) for $1 \mathrm{~h}$ at $37^{\circ} \mathrm{C}$ followed by $200 \mathrm{U} /$ $\mathrm{ml}$ type I collagenase (Sigma-Aldrich, St. Louis, MO, USA) for $4 \mathrm{~h}$ at $37^{\circ} \mathrm{C}$. The sections were maintained in low glucose Dulbecco's Modified Eagle's Medium (Hyclone, Logan, UT, USA) supplemented with $10 \%$ fetal bovine serum, $100 \mathrm{U} / \mathrm{ml}$ penicillin, and $100 \mu \mathrm{g} / \mathrm{ml}$ streptomycin (all from Gibco) in a humidified incubator at $37^{\circ} \mathrm{C}$ and $5 \% \mathrm{CO}_{2}$. Cells derived from explants were passaged by digestion with $0.25 \%$ trypsin. Passage 3 cells were used for the experiments. The morphology of the primary cells was observed visually under a microscope
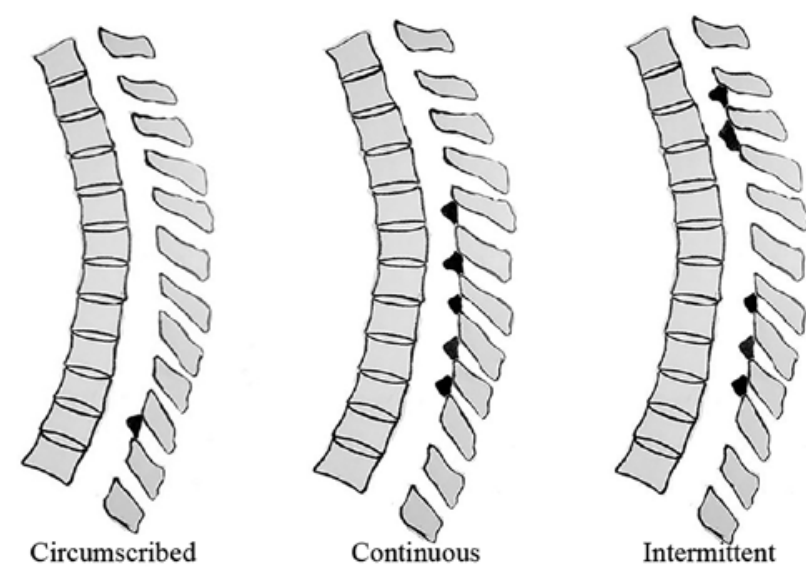

Figure 1. Thoracic ossification of ligament flavum classification based on the lesion distribution as determined by magnetic resonance imaging.

(5221227/293232; Leica, Wetzlar, Germany) and images were obtained under the magnification of x $50, \times 100$ and $\times 200$.

Application of mechanical stretch. The cells were trypsinized and placed on a silicon chamber coated with type I collagen (Flexcell International, Hillsborough, NC, USA) at a density of 10,000 cells $/ \mathrm{cm}^{2}$ and after 3 days, the cells reached confluence. Firstly, the cells derived from 6 patients (TOLF and non-TOLF patients) and were subjected to cyclic mechanical stretch at 0,5 , 10,15 and $20 \%$ by using a equi-biaxial cell-stretching apparatus (Flexcell FX-4000 Tension Plus System; Flexcell International) at $0.5 \mathrm{~Hz}$ and $37^{\circ} \mathrm{C}$ in a humidified atmosphere of $95 \%$ air and $5 \% \mathrm{CO}_{2}$ for 12 and $24 \mathrm{~h}$, and the optimal magnitude of stretch was determined according to the result. The optimal magnitude of stretch was then applied to cells from all the patients for 6 , 12 and $24 \mathrm{~h}$.

ALP activity assay. ALP activity was quantitatively analyzed using the LabAssay ALP kit (Wako, Osaka, Japan) and by staining using a commercial kit (Genmed, Shanghai, China). For the quantitative assay, total cellular protein was isolated from the cultured cells using radioimmunoprecipitation (RIPA) extraction buffer (Applygen Technologies, Beijing, China) and the concentration was determined using the bicinchoninic acid (BCA) method. The extracted protein solution was analyzed for ALP activity according to the manufacturer's instructions, with the activity reported relative to the protein concentration $(\mathrm{U} / \mathrm{mg})$. The cells were stained for ALP activity and ALP-positive cells were blue, while the counterstained nuclei appeared red. Micrographs of 10 random fields were obtained for analysis. Stained areas were measured using Image-Pro Plus 6.0 software (Media Cybernetics, Rockville, MD, USA), and the ratio of stained cells to the number of total cells was determined.

Reverse transcription-quantitative polymerase chain reaction $(R T-q P C R)$. Total RNA was extracted from the cell monolayers using TRIzol reagent (Invitrogen Life Technologies, Carlsbad, CA, USA), and $1 \mu \mathrm{g}$ total RNA was reverse transcribed into cDNA using the GoScript Reverse Transcription System (Promega Corp., Madison, WI, USA). The primers used for amplification are listed in Table II. qPCR was performed in 
Table I. Patient information.

\begin{tabular}{|c|c|c|c|c|c|c|c|c|}
\hline \multirow[b]{2}{*}{ Groups } & \multicolumn{8}{|c|}{ Sample no. } \\
\hline & 1 & 2 & 3 & 4 & 5 & 6 & 7 & 8 \\
\hline \multicolumn{9}{|l|}{ Non-TOLF } \\
\hline Age/gender & $62 / \mathrm{M}$ & $44 / F$ & $58 / \mathrm{M}$ & $52 / \mathrm{M}$ & $44 / \mathrm{M}$ & $42 / \mathrm{M}$ & $52 / \mathrm{M}$ & $43 / \mathrm{F}$ \\
\hline Diagnosis & T11-12 TDH & $\begin{array}{l}\mathrm{T} 8,10,12 \\
\text { fracture }\end{array}$ & $\begin{array}{c}\text { T11-12 } \\
\text { TDH }\end{array}$ & $\begin{array}{l}\mathrm{T} 12 \\
\text { fracture }\end{array}$ & $\begin{array}{l}\mathrm{T} 7-9 \\
\text { fracture }\end{array}$ & $\begin{array}{c}\text { T12-L1 } \\
\text { TDH }\end{array}$ & $\begin{array}{l}\mathrm{T} 12 \\
\text { fracture }\end{array}$ & $\begin{array}{l}\mathrm{T} 6-7 \\
\text { fracture }\end{array}$ \\
\hline \multicolumn{9}{|l|}{$\begin{array}{l}\text { Single-level } \\
\text { TOLF }\end{array}$} \\
\hline Age/gender & 54/M & $44 / \mathrm{F}$ & $65 / \mathrm{F}$ & 63/M & $69 / \mathrm{F}$ & 58/M & $43 / \mathrm{F}$ & 70/M \\
\hline Ossification level & T10-11 & T10-11 & T10-11 & T11-12 & T10-11 & T10-11 & T11-12 & T10-11 \\
\hline \multicolumn{9}{|l|}{$\begin{array}{l}\text { Multiple-level } \\
\text { TOLF }\end{array}$} \\
\hline $\begin{array}{l}\text { Age/gender } \\
\text { Classification }\end{array}$ & $\begin{array}{c}57 / \mathrm{F} \\
\text { Intermittent }\end{array}$ & $\begin{array}{c}59 / \mathrm{F} \\
\text { Intermittent }\end{array}$ & $\begin{array}{c}\text { 61/M } \\
\text { Continuous }\end{array}$ & $\begin{array}{c}\text { 68/M } \\
\text { Continuous }\end{array}$ & $\begin{array}{c}55 / \mathrm{M} \\
\text { Intermittent }\end{array}$ & $\begin{array}{c}59 / \mathrm{F} \\
\text { Intermittent }\end{array}$ & $\begin{array}{c}52 / \mathrm{F} \\
\text { Intermittent }\end{array}$ & $\begin{array}{c}58 / \mathrm{F} \\
\text { Intermittent }\end{array}$ \\
\hline $\begin{array}{l}\text { Ossification } \mathrm{T} \\
\text { level }\end{array}$ & $\mathrm{T} 2-4, \mathrm{~T} 5-7, \mathrm{~T} 10-11$ & $\mathrm{~T} 1-3, \mathrm{~T} 8-11$ & T1-8 & $\mathrm{T} 2-8$ & $\mathrm{~T} 2-5, \mathrm{~T} 9-12$ & $\mathrm{~T} 2-5, \mathrm{~T} 8-11$ & T2-6,T9-L1 & $\mathrm{T} 2-3,6-7,8-12$ \\
\hline
\end{tabular}

Age is presented in year. TOLF, thoracic ossification of ligament flavum; TDH, thoracic disc herniation; M, male; F, female.

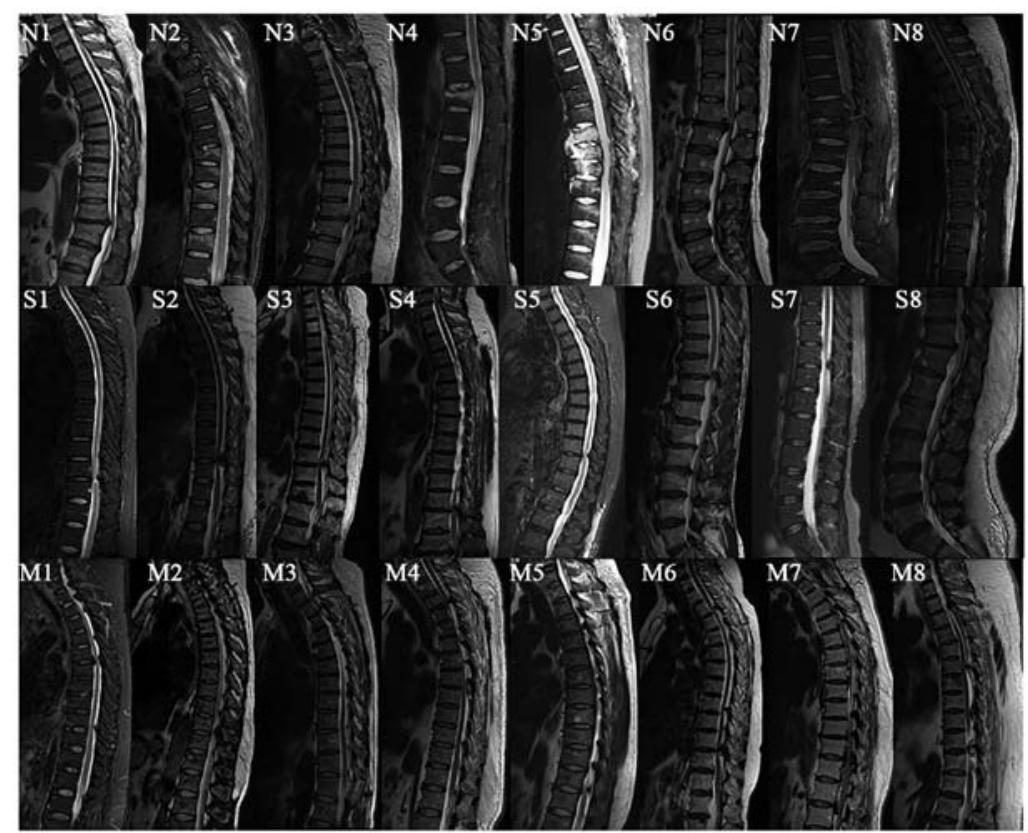

Figure 2. MRI image of patients in the non-thoracic ossification of ligament flavum (TOLF) and single- and multiple-level TOLF groups. N, non-TOLF; $\mathrm{S}$, single-level TOLF; M, multiple-level TOLF; MRI, magnetic resonance imaging. The numbers 1-8 indicate the sample no.

triplicate using SYBR-Green SuperReal PreMix Plus [Tiangen Biotech (Beijing) Co., Ltd., Beijing, China] and the iQ5 PCR system (Bio-Rad Laboratories, Inc., Hercules, CA, USA). The reaction conditions were as follows: $95^{\circ} \mathrm{C}$ for $10 \mathrm{~min}$, and 40 cycles of $95^{\circ} \mathrm{C}$ for $15 \mathrm{sec}$ and $60^{\circ} \mathrm{C}$ for $1 \mathrm{~min}$. Data are represented as cycle threshold $(\mathrm{Ct})$ values. The RNA levels in different samples were compared using the $2^{-\Delta \Delta \mathrm{Ct}}$ method and were normalized to glyceraldehyde-3-phosphate dehydrogenase (GAPDH) levels.

Western blotanalysis. Total cellular protein was isolated from the cultured cells using RIPA extraction buffer and the concentration was determined by BCA assay. A total of $30 \mu \mathrm{g}$ protein per well was separated by $10-15 \%$ SDS-polyacrylamide gel electrophoresis and transferred onto nitrocellulose membranes, which were blocked for $2 \mathrm{~h}$ at $24-25^{\circ} \mathrm{C}$ with $5 \%$ BSA/TBST and then incubated overnight at $4^{\circ} \mathrm{C}$ with the following primary antibodies: rabbit monoclonal anti-BMP2 (1:1,000; ab183729), mouse monoclonal anti-osterix $(1: 1,000$; ab57335), rabbit polyclonal anti-OPN (1:1,000; ab181440) and rabbit monoclonal anti-ALP (1:1,000; ab186422) (all from Abcam, Cambridge, UK); and mouse monoclonal anti-GAPDH (1:2,000; BE0023; Bioeasytech, Beijing, China). 
Table II. Primers used for RT-qPCR.

\begin{tabular}{|c|c|c|c|}
\hline Gene & Primer sequence & Product size (bp) & Annealing temperature $\left({ }^{\circ} \mathrm{C}\right)$ \\
\hline GAPDH & $\begin{array}{l}\text { Forward: 5'-CAGGAGGCATTGCTGATGAT-3' } \\
\text { Reverse: 5'-GAAGGCTGGGGCTCATTT-3' }\end{array}$ & 126 & 60 \\
\hline ALP & $\begin{array}{l}\text { Forward: 5'-AAGGACGCTGGGAAATCTGT-3' } \\
\text { Reverse: 5'-GGGCATCTCGTTGTCTGAGT-3' }\end{array}$ & 117 & 57 \\
\hline BMP2 & $\begin{array}{l}\text { Forward: 5'-TCAAGCCAAACACAAACAGC-3' } \\
\text { Reverse: 5'-GGAGCCACAATCCAGTCATT-3' }\end{array}$ & 105 & 55 \\
\hline Osterix & $\begin{array}{l}\text { Forward: 5'-GAGGTTCACTCGTTCGGATG-3' } \\
\text { Reverse: 5'-TGGTGTTTGCTCAGGTGGT-3' }\end{array}$ & 120 & 56 \\
\hline Runx2 & $\begin{array}{l}\text { Forward: 5'-CCGTCCATCCACTCTACCAC-3' } \\
\text { Reverse: 5'-ATGAAATGCTTGGGAACTGC-3' }\end{array}$ & 139 & 56 \\
\hline OCN & $\begin{array}{l}\text { Forward: 5'-CTCACACTCCTCGCCCTATT-3' } \\
\text { Reverse: 5'-CGCCTGGGTCTCTTCACTAC-3' }\end{array}$ & 143 & 58 \\
\hline OPN & $\begin{array}{l}\text { Forward: 5'-GCCGTGGGAAGGACAGTTAT-3' } \\
\text { Reverse: 5'-GCTCATTGCTCTCATCATTGG-3' }\end{array}$ & 114 & 56 \\
\hline
\end{tabular}

ALP, alkaline phosphatase; BMP2, bone morphogenetic protein-2; Runx-2, Runt-related transcription factor-2; OPN, osteopontin; OCN, osteocalcin.

Immunoreactivity was detected with IRDye $800 \mathrm{cw}$-conjugated goat anti-rabbit/-mouse IgG (1:10,000; LI-COR Biosciences, Lincoln, NE, USA) secondary antibodies and visualized with an Odyssey infrared imaging system (LI-COR Biosciences), with gray values analyzed using Odyssey v3.0 software.

Statistical analysis. In this study, the data are presented as the means \pm standard deviation and were analyzed using SPSS 20.0 software (SPSS, Inc., Chicago, IL, USA). The mRNA expression data were evaluated by one-way analysis of variance (ANOVA) with a post hoc Dunnett's test (compared to $0 \mathrm{~h}$ in the non-TOLF group) and the post hoc Tukey's test for multiple comparisons. Other data sets were evaluated by ANOVA with a post hoc Tukey's test for multiple comparisons. A value of $\mathrm{P}<0.05$ was considered to indicate a statistically significant difference.

\section{Results}

Morphology of primary cells and determination of the optimal mechanical stress level. The primary cells in all 3 groups were long and spindle-shaped and exhibited fibrocyte-like adherent growth (Fig. 3A). Following exposure to different levels $(0,5,10,15$ and $20 \%)$ of cyclic mechanical stress for 12 or $24 \mathrm{~h}$, osteogenic potency was evaluated with the ALP activity assay. In the non-TOLF group, ALP activity remained constant at different levels of cyclic mechanical stress and periods of induction (Fig. 3B and C). However, ALP activity was increased in the TOLF group, particularly upon the application of $15 \%$ mechanical stress for $12 \mathrm{~h}$ (Fig. 3B) and $24 \mathrm{~h}$ (Fig. 3C). We therefore applied a mechanical stress of $15 \%$ for the subsequent experiments.

Changes in ALP activity induced by cyclic mechanical stress. In the absence of cyclic mechanical stress, ALP activity was higher in the multiple-level than in the single-level TOLF and non-TOLF groups $(\mathrm{P}<0.001)$. The activity was slightly higher in the single-level TOLF than in the non-TOLF group, although the difference was not statistically significant. At longer induction times, ALP activity increased in the 2 TOLF groups, with a greater increase observed in the multiple-level group (Fig. 4A).

There were almost no ALP-positive cells in the non-TOLF group regardless of stress application. However, there were many ALP-positive cells in the 2 TOLF groups even in the absence of stress, and their numbers increased with the application time, particularly in the multiple-level TOLF group (Fig. 4B-D). The semi-quantitative analysis of the stained area and positive cells yielded similar results (Fig. 4E and F).

Osteogenesis marker expression is upregulated at the mRNA level by cyclic mechanical stress. The mRNA levels of osteogenesis markers, including ALP, BMP2, osterix, Runx2, OCN and OPN were upregulated by cyclic mechanical stress in the single- and multiple-level TOLF groups, as determined by RT-qPCR. ALP expression was highest in the multiple-level TOLF group, followed by the single-level and non-TOLF groups at $0 \mathrm{~h}$, and it increased over time in both TOLF groups with the application of stress; at $24 \mathrm{~h}$, the ALP expression level was 2.1-fold higher in the multiple-level group than in the single-level group (Fig. 5A). Similar trends were observed for BMP2; at $24 \mathrm{~h}$, the expression level was 2.3-fold higher in the multiple-level group than in the single-level group (Fig. 5B). The mRNA expression of osterix was highest in the multiple-level TOLF group at $0 \mathrm{~h}$, followed by the single-level and non-TOLF groups, although the differences between the groups were not statistically significant. While the application of mechanical stress did not affect the single-level group, the expression level increased in the multiple-level TOLF group relative to the other 2 groups at $12 \mathrm{~h}$, and was approximately 2.1-fold higher than 

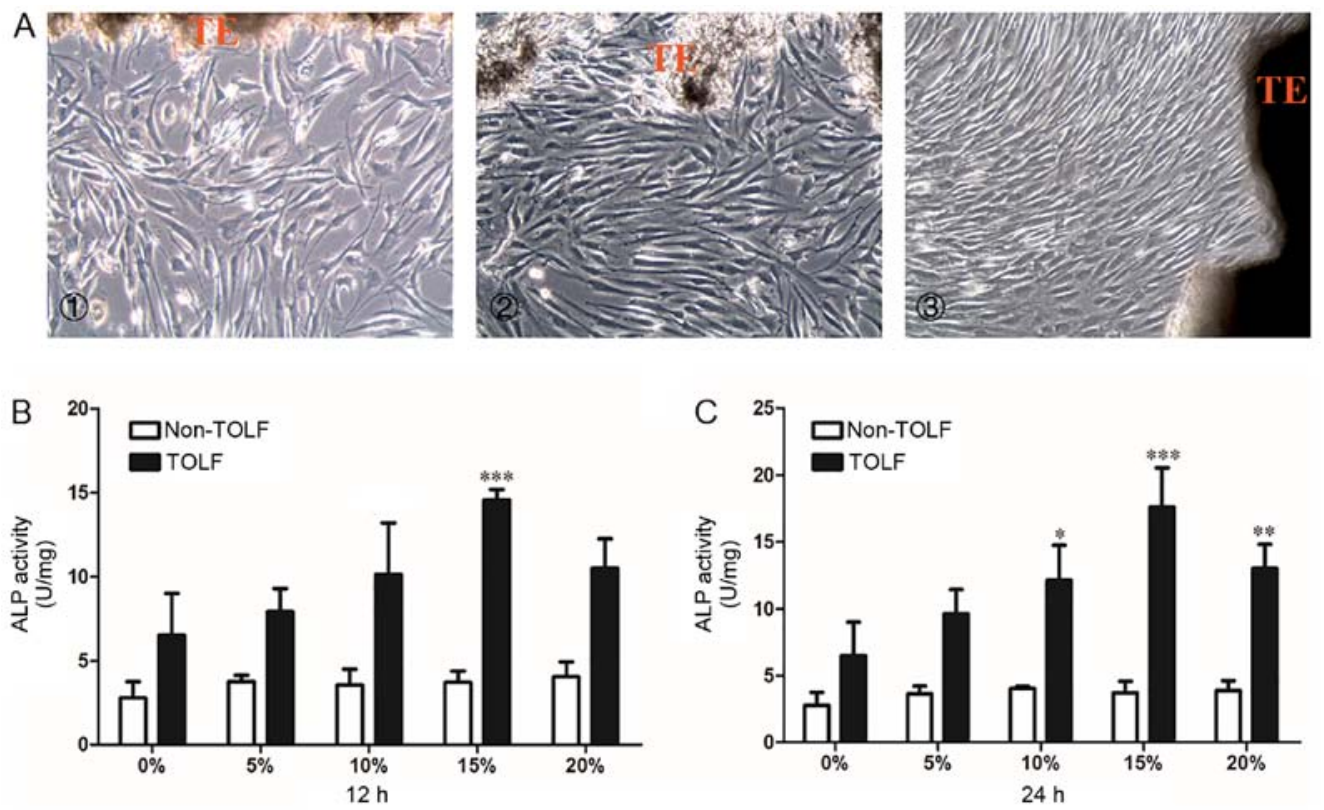

Figure 3. Morphology of primary ligament cells and quantitative analysis of alkaline phosphatase (ALP) activity in determination of optimal stress level. Morphology of primary ligament cells. (A) Cell morphoology in the cells from patients in the different groups: panel 1, non-TOLF gorup; panel 2, single-level TOLF group; and panel 3, multiple-level TOLF goup (x100 magnification). TE, tissue explant. (B and C) Quantitative analysis of ALP activity in TOLF and non-TOLF groups under different strengths of cyclic mechanical stress $(0,5,10,15$ and $20 \%)$ for (B) $12 \mathrm{~h}$ and (C) $24 \mathrm{~h}$ (data are the means \pm standard deviation; $\mathrm{n}=3$ patients/group). ${ }^{*} \mathrm{P}<0.05,{ }^{* *} \mathrm{P}<0.01,{ }^{* * *} \mathrm{P}<0.001$ vs. $0 \%$ in each group. TOLF, thoracic ossification of ligament flavum.

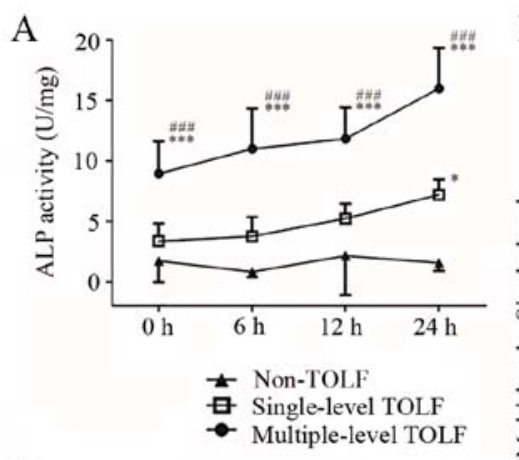

D

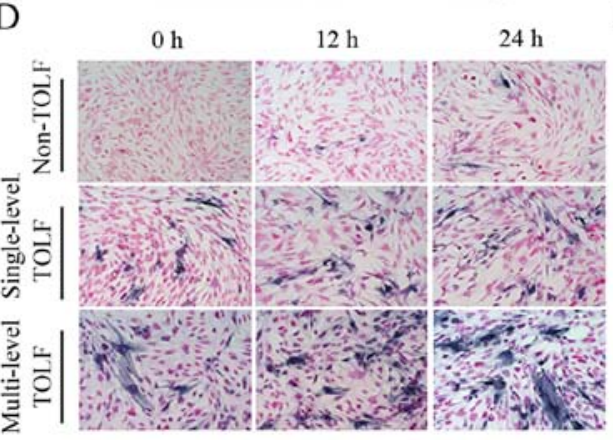

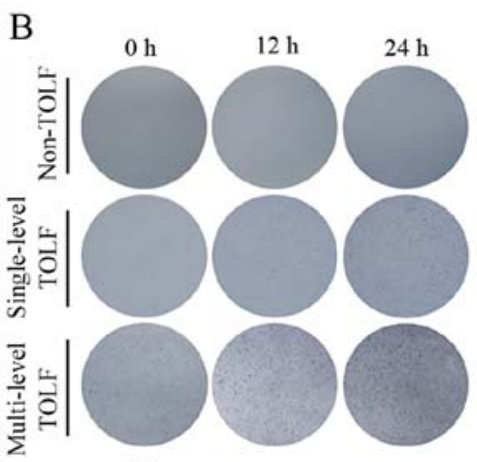

E
C

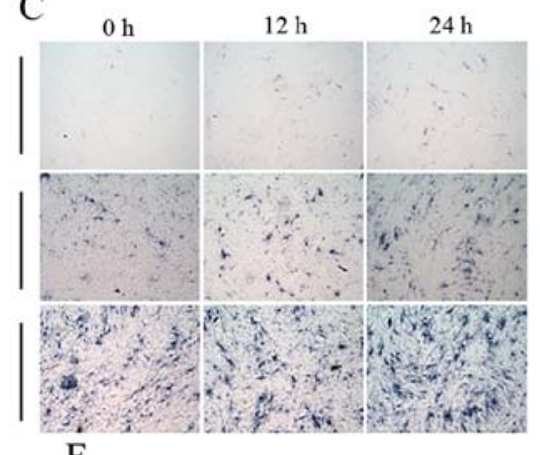

F
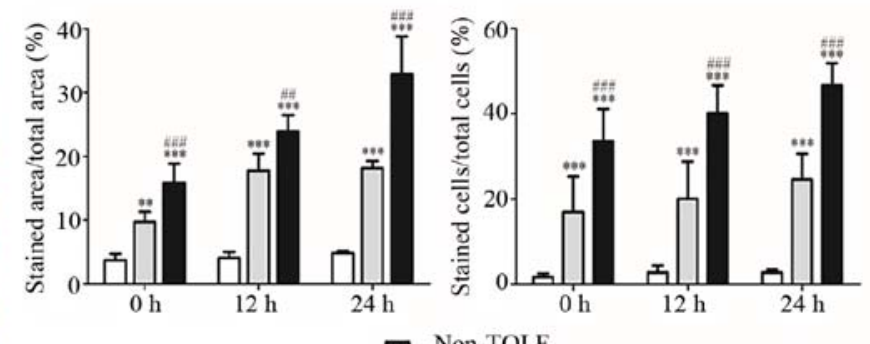

므-TOLF

Single-level TOLF

Figure 4. Change in alkaline phosphatase (ALP) activity induced by cyclic mechanical stress. (A) Quantitative analysis of ALP activity in non-thoracic ossification of ligament flavum (TOLF) and single- and multiple-level TOLF (data are the means \pm standard deviation; $\mathrm{n}=6$ patients/group). ${ }^{*} \mathrm{P}<0.05,{ }^{* * * *} \mathrm{P}<0.001 \mathrm{vs}$. non-TOLF at the same time point. ${ }^{\# \#} \mathrm{P}<0.001$ vs. single-level TOLF at the same time point. (B and D) Images of ALP activity staining: (B) gross observation, (C) light microscopy, and (D) with nuclear counterstaining (x40 magnification for panels C; and x100 magnification for panels D). (E and F) Semi-quantitative analysis of the area of (E) ALP staining and (F) stained cells (data are the means \pm standard deviation; $n=10$ micrographs/group). ${ }^{* * *} \mathrm{P}<0.01,{ }^{* * *} \mathrm{P}<0.001$ vs. non-TOLF at the same time point. ${ }^{\# \#} \mathrm{P}<0.001,{ }^{\# \# \#} \mathrm{P}<0.001$ vs. single-level TOLF at the same time point.

that in the single-level TOLF group at $24 \mathrm{~h}$ (Fig. 5C). In addition, Runx2 expression was higher in the TOLF groups than in the non-TOLF group and it increased with stress application; at 0 and $24 \mathrm{~h}$, the Runx 2 transcript level was higher in the multiple-level group than in the single-level group (Fig. 5D). Likewise, OCN and OPN expression was higher in the TOLF groups than in the non-TOLF group (Fig. 5E and F), and it was increased by stress in the multiple-level TOLF group; OCN 
Table III. Variance analysis of different curves using ANOVA with Tukey's post-hoc test.

\begin{tabular}{lccc}
\hline Gene & $\begin{array}{c}\text { Non-TOLF vs. single-level } \\
\text { TOLF groups }\end{array}$ & $\begin{array}{c}\text { Non-TOLF vs. multiple-level } \\
\text { TOLF groups }\end{array}$ & $\begin{array}{c}\text { Single-level TOLF vs. multiple-level } \\
\text { TOLF groups }\end{array}$ \\
\hline ALP & $\mathrm{ns}$ & $\mathrm{P}<0.001$ & $\mathrm{P}<0.01$ \\
BMP-2 & $\mathrm{ns}$ & $\mathrm{P}<0.001$ & $\mathrm{P}<0.001$ \\
Osterix & $\mathrm{ns}$ & $\mathrm{P}<0.01$ & $\mathrm{P}<0.01$ \\
Runx2 & $\mathrm{ns}$ & $\mathrm{ns}$ & $\mathrm{ns}$ \\
OCN & $\mathrm{ns}$ & $\mathrm{P}<0.05$ & $\mathrm{~ns}$ \\
OPN & $\mathrm{ns}$ & $\mathrm{P}<0.001$ & $\mathrm{P}<0.05$ \\
\hline
\end{tabular}

ns, not significant; ALP, alkaline phosphatase; BMP2, bone morphogenetic protein-2; Runx-2, Runt-related transcription factor-2; OCN, osteocalcin; OPN, osteopontin.

A

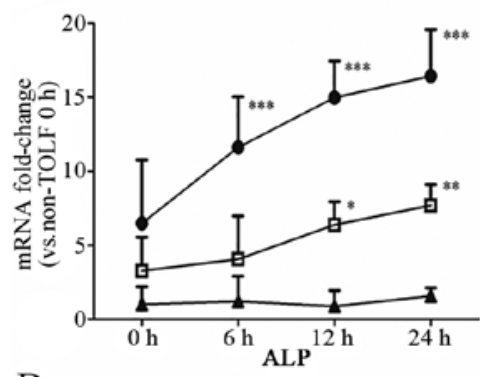

D

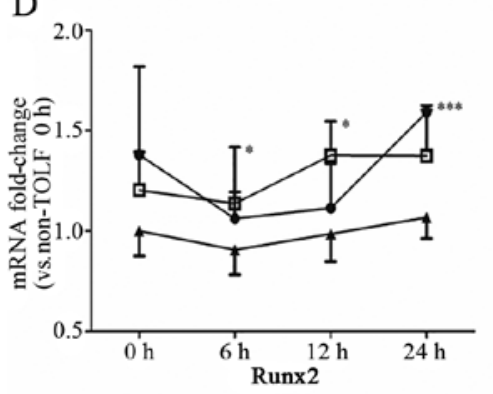

B

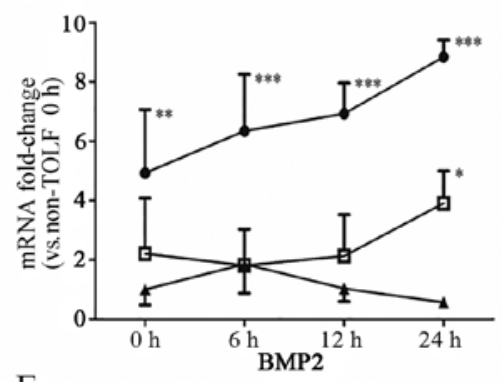

E

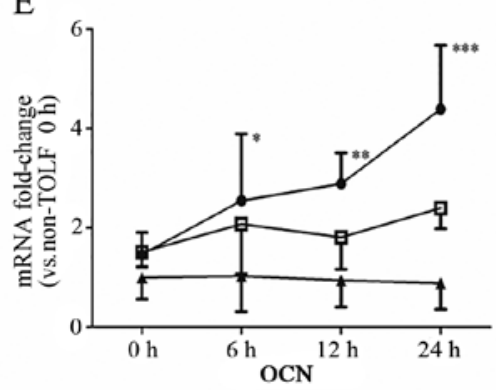

C

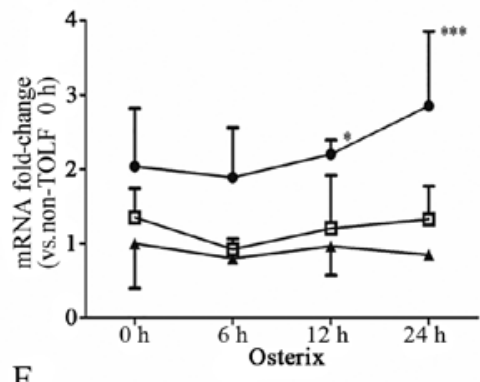

$\mathrm{F}$

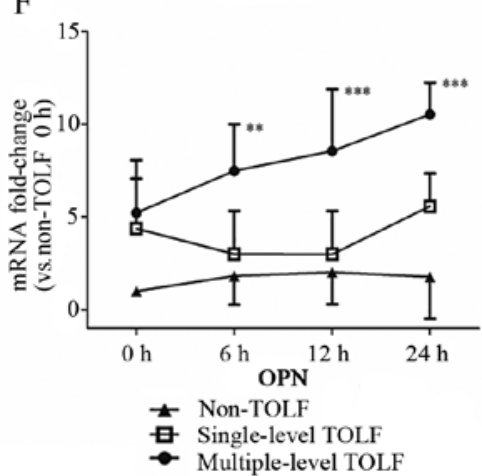

Figure 5. Osteogenic marker expression at the mRNA level. Analysis of mRNA expression levels in cells from patients with non-thoracic ossification of ligament flavum (TOLF) and single- and multiple-level TOLF by RT-qPCR. (A) ALP, (B) bone morphogenetic protein-2 (BMP2), (C) osterix, (D) Runt-related transcription factor-2 (Runx-2), (E) osteocalcin $(\mathrm{OCN})$ and $(\mathrm{F})$ osteopontin $(\mathrm{OPN})$ (data are the means \pm standard deviation; $\mathrm{n}=8 \mathrm{patients} / \mathrm{group}){ }^{*} \mathrm{P}<0.05,{ }^{* *} \mathrm{P}<0.01$, ${ }^{* * *} \mathrm{P}<0.001$ vs. $0 \mathrm{~h}$ in non-TOLF group.

expression was 1.8-fold higher in the multiple-level group than in the single-level group at $24 \mathrm{~h}$.

Pairwise comparisons among the 3 groups indicated that the expression of ALP, BMP2, osterix and OPN was higher in the multiple-level TOLF group than in the other 2 groups. OCN expression was higher in the multiple-level TOLF group than in the non-TOLF group, whereas there were no differences in Runx 2 expression among the 3 groups. Moreover, the expression levels of all markers were similar between single-level and non-TOLF groups (Table III).

Osteogenic marker expression is upregulated at the protein level by cyclic mechanical stress. The protein levels of osteogenic markers were assessed by western blot analysis (Fig. 6A). ALP and osterix were more highly expressed in the multiple-level TOLF group than in the other 2 groups, and their expression increased with the application of mechanical stress to levels that were significantly higher at $12 \mathrm{~h}$ (Fig. 6B and C). The expression of both markers was higher in the single-level TOLF group than in the non-TOLF group. The BMP2 and OPN levels were higher in the TOLF groups than in the non-TOLF group. However, their levels in the single-level TOLF group were not altered with stress application (Fig. 6D and E).

\section{Discussion}

Many studies have demonstrated the critical role of mechanical stress in the development of TOLF $(7,15,22-25)$. We previ- 

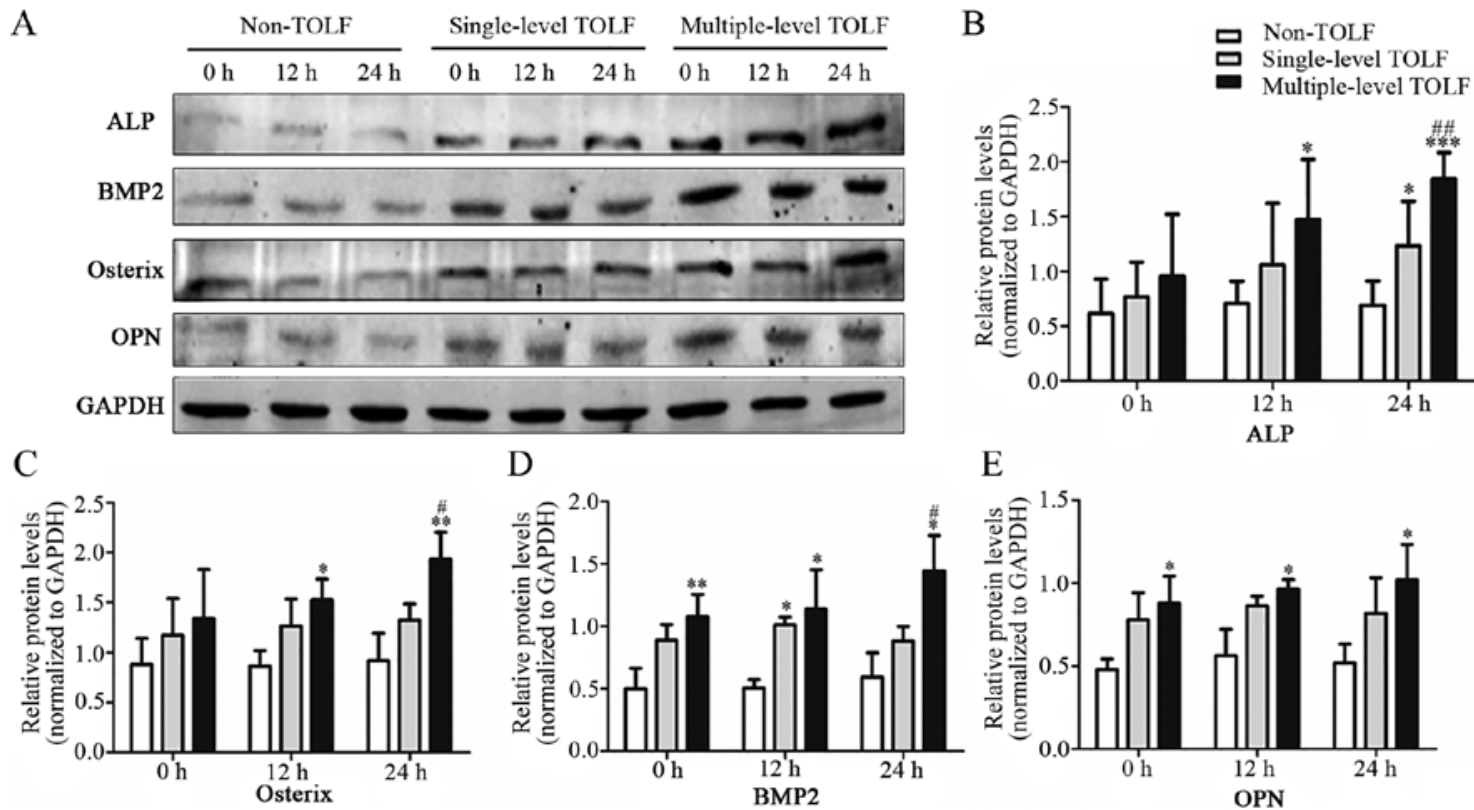

D

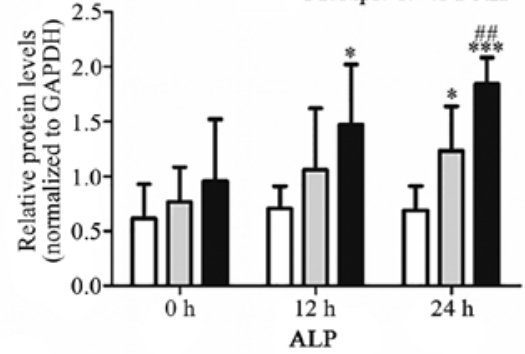

E
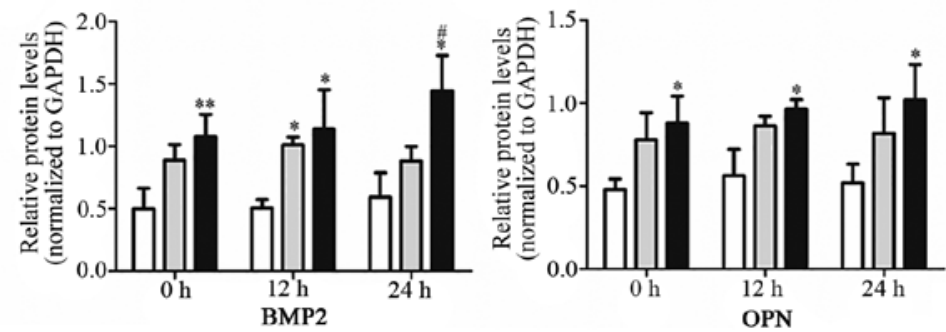

Figure 6. Osteogenic marker expression at the protein level. (A) Western blot analysis of thoracic ossification of ligament flavum (TOLF) and non-TOLF samples. (B and E) Semi-quantitative analysis of protein expression in non-TOLF and single- and multiple-level TOLF. (B) Alkaline phosphatase (ALP), (C) osterix, (D) bone morphogenetic protein-2 (BMP2), and (E) osteopontin (OPN) (mean \pm standard deviation; $\mathrm{n}=3$ patients $/$ group). ${ }^{*} \mathrm{P}<0.05,{ }^{* * *} \mathrm{P}<0.01,{ }^{* * *} \mathrm{P}<0.001$ vs. non-TOLF at the same time point. ${ }^{\#} \mathrm{P}<0.05,{ }^{\# \#} \mathrm{P}<0.01 \mathrm{vs}$. single-level TOLF at the same time point.

ously reported that mechanical stress induced the osteogenic differentiation of ligament cells derived from patients with TOLF, which in turn promoted OLF, leading us to conclude that stress facilitated, but did not initiate the development of TOLF (10). In the present study, we used cyclic stress to induce osteogenesis in fibroblasts derived from non-TOLF and single and multiple-level TOLF in order to assess genetic differences in the osteogenic differentiation potency.

Although the morphology of ligament cells derived from the 3 groups was similar, the cells differed in terms of osteogenic potency, possibly due to cytogenetic differences. Ligament cells from patients with TOLF already possess certain osteoblast characteristics, including the upregulation of specific markers, whereas cells from non-TOLF patients exhibit a fibroblast phenotype $(3,26-28)$. OCN and collagen type II are expressed in cells derived from patients with OLF, but not cells derived from non-OLF patients; cells derived from patients with OLF would thus present an osteoblast and chondrocyte phenotype (29). Another study reported that stress induced the mineralization of cells from patients with TOLF (10). These results demonstrate that cells from patients with TOLF have a greater potential for differentiation from fibroblasts to osteoblasts or chondrocytes.

Clinically, OLF mainly occurs in the thoracic spine, but rarely in the cervical and lumbar vertebrae that have a greater range of motion, which possibly indicates that ligament cells from patients with TOLF are sensitive to a certain range of cyclic mechanical stress in osteogenic induction. In addition, the degree of mechanical stress required for osteogenic induction has been investigated in several studies (30-32). For example, an equi-biaxial stretch chamber applying $9 \%$ mechanical stress was determined as optimal for inducing the differentiation of cells from patients with TOLF (10). On the other hand, $20 \%$ stress has been applied to cells from patients with TOLF and OPLL using the Flexcell FX-3000 and -4000 systems, respectively, although these studies did not explore the optimal range of mechanical stress $(15,33)$. The differences between these devices, as well as the reactivity of cells derived from different tissues underscored the importance of exploring the optimal level of mechanical stress in the present study. ALP is a sensitive and specific indicator of the early stage of osteoblast differentiation (34); we found that $15 \%$ stress produced the highest ALP activity, indicating that this strength effectively induced osteogenesis of ligament cells from patients with TOLF. We also found that ALP activity was higher in the 2 TOLF groups than in the non-TOLF group, with the highest activity observed in the multiple-level group. Accordingly, a larger area of positive ALP staining, corresponding to a higher osteogenic potency, was observed in this group as compared to the single-level TOLF group.

BMP2 is an osteogenic factor that has been implicated in the ossification of the spinal ligament. BMP and its receptors have been found to be widely expressed in OLF tissues, but to be only partially expressed in the region connecting the ligamentum flavum and vertebrae in non-OLF tissues (35), leading these investigators to conclude that the aberrant expression of BMP and its receptors contributes to OLF. Similarly, another study reported an abundance of BMP2-positive fibroblasts distributed in areas of calcification and ossification in TOLF (14). In this study, we found that the BMP2 mRNA level was higher in the multiple-level group than in the single-level and non-TOLF groups at $0 \mathrm{~h}$ and that it increased with application of cyclic mechanical stress. These results demonstrate that BMP2 plays an important role in the osteogenic differentiation of cells from patients with TOLF and that differences in expression may account for the distinct prognoses of single- and multiple-level TOLF. 
Runx 2 is a transcription factor that regulates osteoblast differentiation. In a previous study, Runx 2 expression was found to be higher in OLF than in the control and was mainly expressed in hyperplastic and hypertrophic cartilage cells (7). In another study, cyclic tensile strain applied for $24 \mathrm{~h}$ increased Runx 2 and OPN mRNA levels in cells from OLF sections, whereas similar mechanical stress had negligible effects on cells from non-OLF sections (15). In the present study, Runx2 expression was similar in the multiple- and single-level TOLF, and higher than that in the non-TOLF group, indicating that Runx 2 expression cannot be used as a marker for distinguishing the osteogenic potency of single- and multiple-level TOLF.

Osterix is a transcription factor activated upon mechanical stress that regulates the transcription of osteogenesis-related genes. Our previous study showed that mechanical stress induced osterix and Runx 2 overexpression in TOLF cells (10). It has also been reported that osterix is more highly expressed in OLF- than in non-OLF-derived cells and is mainly distributed in cartilage cells located in the calcified cartilage and fibrocartilage layers (7). Osterix has been shown to promote osteoblast differentiation and mineralization at a heterotopic site (36). In this study, osterix expression was higher in the multiple-level group as compared to the single-level TOLF group at $0 \mathrm{~h}$ and increased with the application of mechanical stress in the former, but not in the latter group, suggesting that osterix can serve as a marker for multiple-level TOLF.

OCN is an extracellular matrix protein that reflects the status of the process of osteogenesis (37). OPN is secreted as an adhesive glycophosphoprotein and modulates matrix mineralization in mechano-transduction (38). Previous studies have reported that OCN and OPN expression increase with the application of mechanical stress. This was confirmed by the results presented in this study: at an early stage of mechanical stress, the OCN and OPN levels were comparable in the 2 TOLF groups; however, over time, the levels were upregulated to a greater degree in the multiple-level than in the singe-level group. This indicates that the osteogenic differentiation of multiple-level TOLF-derived cells is more active under the application of cyclic mechanical stress.

Clinically, multiple-level TOLF differs from single-level lesions in terms of disease progression and clinical outcomes, and multiple-level TOLF has a poor prognosis and may continue to develop after surgical resection $(12,39,40)$, suggesting that the osteogenic potency may be differ between them, which is consistent with our experimental results. There were some limitations to this study. Firstly, the mechanistic basis for differences in osteogenic potency between multiple- and single-level TOLF requires more detailed investigation, such as bioinformatics analysis of gene expression profiles, and we aim to do this in future studies. In addition, in the current study, we examined changes in osteogenic potency and gene expression in cells from patients with TOLF in response to mechanical stress in vitro, and did not consider other types of stress that are present in vivo, including compression, twisting and shear forces. Therefore, additional studies using an in vivo TOLF model are required.

In conclusion, this study demonstrated that ligament cells from patients with TOLF were sensitive to a certain range of mechanical stress in osteogenic differentiation. Single- and multiple-level TOLF differed in terms of osteo- genic potency and related gene expression under cyclic stress, with the latter exhibiting a greater potency for osteogenic differentiation that may be related to the different pathogenesis of them and contribute to the different clinical outcome.

\section{Acknowledgements}

This study was supported by the National Natural Science Foundation of China (grant nos. 81272031, 81071505 and 81572101). We acknowledge the assistance of Peking University Third Hospital Central Laboratory with the technical guidance.

\section{References}

1. Sato T, Kokubun S, Tanaka Y and Ishii Y: Thoracic myelopathy in the Japanese: Epidemiological and clinical observations on the cases in Miyagi Prefecture. Tohoku J Exp Med 184: 1-11, 1998.

2. Guo JJ, Luk KD, Karppinen J, Yang $\mathrm{H}$ and Cheung KM: Prevalence, distribution, and morphology of ossification of the ligamentum flavum: A population study of one thousand seven hundred thirty-six magnetic resonance imaging scans. Spine 35: 51-56, 2010.

3. Kudo S, Ono M and Russell WJ: Ossification of thoracic ligamenta flava. AJR Am J Roentgenol 141: 117-121, 1983.

4. Lang N, Yuan HS, Wang HL, Liao J, Li M, Guo FX, Shi S and Chen ZQ: Epidemiological survey of ossification of the ligamentum flavum in thoracic spine: CT imaging observation of 993 cases. Eur Spine J 22: 857-862, 2013.

5. Mobbs RJ and Dvorak M: Ossification of the ligamentum flavum: diet and genetics. J Clin Neurosci 14: 703-705, 2007.

6. Fan D, Chen Z, Chen Y and Shang Y: Mechanistic roles of leptin in osteogenic stimulation in thoracic ligament flavum cells. J Biol Chem 282: 29958-29966, 2007.

7. Uchida K, Yayama T, Cai HX, Nakajima H, Sugita D, Guerrero AR, Kobayashi S, Yoshida A, Chen KB and Baba H: Ossification process involving the human thoracic ligamentum flavum: Role of transcription factors. Arthritis Res Ther 13: R144, 2011.

8. Okada K, Oka S, Tohge K, Ono K, Yonenobu K and Hosoya T: Thoracic myelopathy caused by ossification of the ligamentum flavum. Clinicopathologic study and surgical treatment. Spine 16: 280-287, 1991.

9. Maigne JY, Ayral X and Guérin-Surville H: Frequency and size of ossifications in the caudal attachments of the ligamentum flavum of the thoracic spine. Role of rotatory strains in their development. An anatomic study of 121 spines. Surg Radiol Anat 14: 119-124, 1992.

10. Fan D, Chen Z, Wang D, Guo Z, Qiang Q and Shang Y: Osterix is a key target for mechanical signals in human thoracic ligament flavum cells. J Cell Physiol 211: 577-584, 2007.

11. Gao R, Yuan W, Yang L, Shi G and Jia L: Clinical features and surgical outcomes of patients with thoracic myelopathy caused by multilevel ossification of the ligamentum flavum. Spine J 13: 1032-1038, 2013.

12. Kawaguchi Y, Yasuda T, Seki S, Nakano M, Kanamori M, Sumi S and Kimura T: Variables affecting postsurgical prognosis of thoracic myelopathy caused by ossification of the ligamentum flavum. Spine J 13: 1095-1107, 2013.

13. Li F, Chen Q and Xu K: Surgical treatment of 40 patients with thoracic ossification of the ligamentum flavum. J Neurosurg Spine 4: 191-197, 2006.

14. Yayama T, Uchida K, Kobayashi S, Kokubo Y, Sato R, Nakajima H, Takamura T, Bangirana A, Itoh H and Baba H: Thoracic ossification of the human ligamentum flavum: Histopathological and immunohistochemical findings around the ossified lesion. J Neurosurg Spine 7: 184-193, 2007.

15. Cai HX, Yayama T, Uchida K, Nakajima H, Sugita D, Guerrero AR, Yoshida A and Baba H: Cyclic tensile strain facilitates the ossification of ligamentum flavum through $\beta$-catenin signaling pathway: In vitro analysis. Spine 37: E639-E646, 2012.

16. Kim HN, Min WK, Jeong JH, Kim SG, Kim JR, Kim SY, Choi JY and Park BC: Combination of Runx2 and BMP2 increases conversion of human ligamentum flavum cells into osteoblastic cells. BMB Rep 44: 446-451, 2011. 
17. Kong Q, Ma X, Li F, Guo Z, Qi Q, Li W, Yuan H, Wang Z and Chen Z: COL6A1 polymorphisms associated with ossification of the ligamentum flavum and ossification of the posterior longitudinal ligament. Spine 32: 2834-2838, 2007.

18. Liu Y, Zhao Y, Chen Y, Shi G and Yuan W: RUNX2 polymorphisms associated with OPLL and OLF in the Han population. Clin Orthop Relat Res 468: 3333-3341, 2010.

19. Kudo H, Furukawa K, Yokoyama T, Ono A, Numasawa T, Wada K, Tanaka S, Asari T, Ueyama K, Motomura S and Toh S: Genetic differences in the osteogenic differentiation potency according to the classification of ossification of the posterior longitudinal ligament of the cervical spine. Spine 36: 951-957, 2011.

20. Chen ZQ, Dang GT, Liu XG and Cai QL: The choice of treatment for ossification of ligamentum flavum of the thoracic spine. Chin J Orthop 19: 197-200, 1999 (In Chinese)

21. Yin X, Chen Z, Guo Z, Liu X and Yu H: Tissue transglutaminase expression and activity in human ligamentum flavum cells derived from thoracic ossification of ligamentum flavum. Spine 35: E1018-E1024, 2010.

22. Ahn DK, Lee S, Moon SH, Boo KH, Chang BK and Lee JI: Ossification of the ligamentum flavum. Asian Spine J 8: 89-96, 2014.

23. Tsukamoto N, Maeda T, Miura H, Jingushi S, Hosokawa A, Harimaya K, Higaki H, Kurata K and Iwamoto Y: Repetitive tensile stress to rat caudal vertebrae inducing cartilage formation in the spinal ligaments: A possible role of mechanical stress in the development of ossification of the spinal ligaments. J Neurosurg Spine 5: 234-242, 2006

24. Iwasawa $T$, Iwasaki $K$, Sawada $T$, Okada A, Ueyama $K$, Motomura S, Harata S, Inoue I, Toh S and Furukawa KI: Pathophysiological role of endothelin in ectopic ossification of human spinal ligaments induced by mechanical stress. Calcif Tissue Int 79: 422-430, 2006.

25. Nakatani T, Marui T, Hitora T, Doita M, Nishida $K$ and Kurosaka M: Mechanical stretching force promotes collagen synthesis by cultured cells from human ligamentum flavum via transforming growth factor-beta1. J Orthop Res 20: 1380-1386, 2002.

26. Hoshi K, Amizuka N, Sakou T, Kurokawa T and Ozawa H: Fibroblasts of spinal ligaments pathologically differentiate into chondrocytes induced by recombinant human bone morphogenetic protein-2: Morphological examinations for ossification of spinal ligaments. Bone 21: 155-162, 1997.

27. Iwasaki K, Furukawa KI, Tanno M, Kusumi T, Ueyama K, Tanaka M, Kudo H, Toh S, Harata S and Motomura S: Uni-axial cyclic stretch induces Cbfa1 expression in spinal ligament cells derived from patients with ossification of the posterior longitudinal ligament. Calcif Tissue Int 74: 448-457, 2004.
28. Ishida Y and Kawai S: Characterization of cultured cells derived from ossification of the posterior longitudinal ligament of the spine. Bone 14: 85-91, 1993.

29. Zhong ZM and Chen JT: Phenotypic characterization of ligamentum flavum cells from patients with ossification of ligamentum flavum. Yonsei Med J 50: 375-379, 2009.

30. Tanno M, Furukawa KI, Ueyama K, Harata S and Motomura S: Uniaxial cyclic stretch induces osteogenic differentiation and synthesis of bone morphogenetic proteins of spinal ligament cells derived from patients with ossification of the posterior longitudinal ligaments. Bone 33: 475-484, 2003.

31. Ohishi H, Furukawa K, Iwasaki K, Ueyama K, Okada A, Motomura S, Harata S and Toh S: Role of prostaglandin I2 in the gene expression induced by mechanical stress in spinal ligament cells derived from patients with ossification of the posterior longitudinal ligament. J Pharmacol Exp Ther 305: 818-824, 2003.

32. Furukawa K: Current topics in pharmacological research on bone metabolism: Molecular basis of ectopic bone formation induced by mechanical stress. J Pharmacol Sci 100: 201-204, 2006.

33. Zhang W, Wei P, Chen Y, Yang L, Jiang C, Jiang P and Chen D: Down-regulated expression of vimentin induced by mechanical stress in fibroblasts derived from patients with ossification of the posterior longitudinal ligament. Eur Spine J 23: 2410-2415, 2014.

34. Pagani F, Francucci CM and Moro L: Markers of bone turnover: Biochemical and clinical perspectives. J Endocrinol Invest 28 (Suppl 10): 8-13, 2005.

35. Hayashi K, Ishidou Y, Yonemori K, Nagamine T, Origuchi N, Maeda S, Imamura T, Kato M, Yoshida H, Sampath TK, et al: Expression and localization of bone morphogenetic proteins (BMPs) and BMP receptors in ossification of the ligamentum flavum. Bone 21: 23-30, 1997.

36. Fu H, Doll B, McNelis T and Hollinger JO: Osteoblast differentiation in vitro and in vivo promoted by Osterix. J Biomed Mater Res A 83: 770-778, 2007.

37. Komaki M, Karakida T, Abe M, Oida S, Mimori K, Iwasaki K, Noguchi K, Oda S and Ishikawa I: Twist negatively regulates osteoblastic differentiation in human periodontal ligament cells. J Cell Biochem 100: 303-314, 2007.

38. Ishijima M, Tsuji K, Rittling SR, Yamashita T, Kurosawa $H$, Denhardt DT, Nifuji A, Ezura Y and Noda M: Osteopontin is required for mechanical stress-dependent signals to bone marrow cells. J Endocrinol 193: 235-243, 2007.

39. Inamasu $\mathbf{J}$ and Guiot $\mathrm{BH}$ : A review of factors predictive of surgical outcome for ossification of the ligamentum flavum of the thoracic spine. J Neurosurg Spine 5: 133-139, 2006.

40. He S, Hussain N, Li S and Hou T: Clinical and prognostic analysis of ossified ligamentum flavum in a Chinese population. J Neurosurg Spine 3: 348-354, 2005 